\title{
Ticagrelor: the evidence for its clinical potential as an oral antiplatelet treatment for the reduction of major adverse cardiac events in patients with acute coronary syndromes
}

This article was published in the following Dove Press journal:

Core Evidence

16 March 2011

Number of times this article has been viewed

\section{Bernardo Lombo' José G Díez ${ }^{2}$}

'Department of Medicine, Yale School of Medicine, New Haven, CT, USA; ${ }^{2}$ Section of Cardiology, Baylor College of Medicine and the Texas Heart Institute at St. Luke's Episcopal Hospital, Houston, TX, USA
Introduction: Ticagrelor, the first direct-acting, reversibly binding oral P2Y12 receptor antagonist, appears to have a favorable efficacy and safety profile.

Aims: To update the evidence and provide an overview of the available data on ticagrelor. Evidence review: Peer reviewed articles published and listed under Medline Search, and published updated guidelines for pharmacotherapies in acute coronary syndromes were reviewed.

Place in therapy: Clinical evidence is increasing to support the use of new thienopyridines and the direct-acting P2Y12 receptor in the setting of acute coronary syndromes.

Conclusion: The options for drugs to inhibit the platelet P2Y12 receptor for adenosine diphosphate are rapidly expanding. Ticagrelor has shown benefits in clinical trials. Its rapid onset of platelet inhibition and short half-life make it an attractive alternative to thienopyridines, especially when rapid inhibition of platelet aggregation or its quick reversal are required.

Keywords: platelet, acute coronary syndromes, antiplatelet, coronary artery disease, percutaneous coronary intervention, stent

Core evidence clinical impact summary for ticagrelor and the reduction of major adverse cardiac events in patients with acute coronary syndromes

\begin{tabular}{|c|c|c|}
\hline Outcome measure & Evidence & Implications \\
\hline \multicolumn{3}{|c|}{ Disease-oriented evidence } \\
\hline Platelet aggregation & $\begin{array}{l}\text { Ticagrelor achieved greater } \\
\text { levels of inhibition than } \\
\text { did clopidogrel (4 hours } \\
\text { after dosing [mean } \pm \text { SD]: } \\
\text { ticagrelor } 90 \mathrm{mg}, 79 \%[ \pm 22 \%] \text {, } \\
\text { ticagrelor } 180 \mathrm{mg}, 95 \%[ \pm 8 \%] \text {, } \\
\text { clopidogrel, } 64 \%[ \pm 22 \%])\end{array}$ & $\begin{array}{l}\text { Better inhibition of platelet } \\
\text { aggregation may improve } \\
\text { patient outcomes }\end{array}$ \\
\hline $\begin{array}{l}\text { Composite of death } \\
\text { from vascular causes }\end{array}$ & $\begin{array}{l}9.8 \% \text { of patients receiving } \\
\text { ticagrelor compared with } \\
\text { II.7\% of those receiving } \\
\text { clopidogrel }(\mathrm{HR}), 0.84 ; 95 \% \\
\text { confidence interval }[\mathrm{Cl}] \\
0.77-0.92 ; \mathrm{P}<0.00 \mathrm{I})\end{array}$ & $\begin{array}{l}\text { In patients with ACS with } \\
\text { or without ST-segment } \\
\text { elevation, treatment with } \\
\text { ticagrelor as compared with } \\
\text { clopidogrel significantly } \\
\text { reduced the rate of death } \\
\text { from vascular causes }\end{array}$ \\
\hline
\end{tabular}

(Continued)
Correspondence: José G Díez Section of Cardiology, Baylor College of Medicine and the Texas Heart Institute at St. Luke's Episcopal Hospital, Houston, TX, USA

$\mathrm{Tel}+\mathrm{I} 7137980280$

Fax +I 7/37980270

Email jgdiez@mac.com 


\begin{tabular}{|c|c|c|}
\hline \multicolumn{3}{|l|}{ (Continued) } \\
\hline Outcome measure & Evidence & Implications \\
\hline $\begin{array}{l}\text { Patients with ACS undergoing } \\
\text { planned invasive evaluation }\end{array}$ & $\begin{array}{l}\text { Cardiovascular death, MI, } \\
\text { or stroke occurred in } \\
\text { fewer patients in the } \\
\text { ticagrelor group than in } \\
\text { the clopidogrel group } \\
\text { (569 [event rate at } 360 \text { days, } \\
9.0 \% \text { ] vs } 668 \text { [ } 10.7 \% \text {, } \\
\text { HR } 0.84,95 \% \text { Cl: } 0.75-0.94 \text {; } \\
P=0.0025 \text { ) }\end{array}$ & $\begin{array}{l}\text { When using a more potent } \\
\text { ADP inhibitor in the setting } \\
\text { of ACS and following an } \\
\text { invasive strategy, ticagrelor } \\
\text { appears to be the better } \\
\text { option }\end{array}$ \\
\hline \multicolumn{3}{|l|}{ Patient-oriented evidence } \\
\hline Bleeding complications & $\begin{array}{l}\text { No significant difference in } \\
\text { the rates of major bleeding } \\
\text { was found between the } \\
\text { ticagrelor and clopidogrel } \\
\text { groups ( } 11.6 \% \text { and } I I .2 \% \text {, } \\
\text { respectively; } P=0.43 \text { ), but } \\
\text { ticagrelor was associated } \\
\text { with a higher rate of major } \\
\text { bleeding not related to } \\
\text { CABG ( } 4.5 \% \text { vs } 3.8 \% \text {; } \\
P=0.03) \text {, including more } \\
\text { instances of fatal intracranial } \\
\text { bleeding }\end{array}$ & $\begin{array}{l}\text { In patients treated with } \\
\text { ticagrelor compared to } \\
\text { clopidogrel there is no } \\
\text { increase in the rate of overal } \\
\text { major bleeding but there } \\
\text { is an increase in the rate } \\
\text { of non-procedure-related } \\
\text { bleeding }\end{array}$ \\
\hline $\begin{array}{l}\text { Effects on cardiac rhythm } \\
\text { and conduction }\end{array}$ & $\begin{array}{l}\text { The incidence of ventricular } \\
\text { pauses }>3 \text { seconds } \\
\text { identified during Holter } \\
\text { monitoring during the first } \\
\text { week of therapy was } 5.8 \% \\
\text { for patients given ticagrelor } \\
\text { and } 3.6 \% \text { for patients given } \\
\text { clopidogrel }(P=0.01) \text {. }\end{array}$ & $\begin{array}{l}\text { Precaution in patients with } \\
\text { bradyarrhythmias }\end{array}$ \\
\hline Dyspnea & $\begin{array}{l}\text { Absolute } 6 \% \text { increase in } \\
\text { the incidence of dyspnea in } \\
\text { patients treated with ticagrelor }\end{array}$ & $\begin{array}{l}\text { It may affect long-term } \\
\text { compliance if the agent is } \\
\text { to be used routinely }\end{array}$ \\
\hline Quality of life measures & Not available & \\
\hline Economic evidence & Not available & \\
\hline
\end{tabular}

Abbreviations: $C A B G$, coronary artery bypass graft; $A C S$, acute coronary syndromes; ADP; adenosine-diphosphate; $\mathrm{Ml}$, myocardial infarction; $\mathrm{HR}$, hazard ratio; $\mathrm{Cl}$, confidence interval.

\section{Introduction}

The use of dual antiplatelet therapy has been fundamental in improving outcomes in patients with atherothrombotic events, and the combined use of aspirin and thienopyridines has been extensively studied. Although clopidogrel, the main type of thienopyridine in use today, has been shown to be beneficial, it also has limitations - specifically, the variability in response to platelet inhibition that some patients may have due to metabolic or pharmacologic interactions and genetic polymorphisms. These limitations combined with clopidogrel's association with decreased efficacy have served as the rationale for the development of new P2Y12 agents, which appear to have superior pharmacodynamic profiles.
Ticagrelor, the first direct-acting, reversibly binding oral P2Y12 receptor antagonist, appears to have a favorable efficacy and safety profile. Results of the Platelet Inhibition and Patient Outcomes (PLATO) trial, ${ }^{1}$ showed patients with acute coronary syndromes (ACS) had improved outcomes with ticagrelor compared with clopidogrel. Currently, ticagrelor is being reviewed by the US Food and Drug Administration (FDA) as a P2Y12 receptor blocker for the treatment of patients with coronary artery disease. (To date, landmark trials have evaluated its use only in ACS.) Its initial approval in the United States was delayed by the FDA because of a lack of benefit observed in US patients. As with any pharmacologic agent, ticagrelor has its advantages and limitations. Given its 
lack of extensive clinical use outside the tight constraints of clinical trials, there are many unknowns, and routine use of the drug in patients outside of clinical trials will require careful postmarketing surveillance. The following review describes the available evidence for ticagrelor.

\section{Acute coronary syndromes and the need for antithrombin and antiplatelet therapies}

The management of unstable angina and non-ST-segmentelevation myocardial infarction (UA/NSTEMI) has evolved substantially in recent years. New antithrombotic options include low-molecular-weight heparins, Xa inhibitors, direct thrombin inhibitors, thienopyridines, and glycoprotein (GP) $\mathrm{IIb} / \mathrm{III}$ a antagonists. In addition, the use of percutaneous interventions in patients with UA/NSTEMI has become a dominant strategy, particularly at tertiary care centers. Recent data from the Can Rapid Risk Stratification of Unstable Angina Patients Suppress Adverse Outcomes with Early Implementation of the ACC/AHA Guidelines (CRUSADE) ${ }^{2}$ registry show that fully $86 \%$ of patients with UA/NSTEMI will be sent to the catheterization laboratory, with $70 \%$ of patients undergoing angiography within 48 hours and 55\% ultimately undergoing percutaneous coronary intervention (PCI) $-46 \%$ of them within 48 hours.

Procedural anticoagulation is believed to be an important adjunctive therapy for PCI. Traditionally, the presence of thrombus has been viewed as a main risk factor for adverse outcomes after interventional procedures. Results of a number of studies have shown that angiographic evidence of pre-existing thrombus before angioplasty, although infrequent $(<4 \%)$, may double or triple the likelihood of procedural failure. ${ }^{3-5}$ Patients with unstable angina undergoing angioplasty in the setting of angiographically demonstrable thrombus are also at higher risk of abrupt vessel closure and have worse in-hospital clinical outcomes. ${ }^{6}$

Thus, we have a paradox. On the one hand, we are performing more PCIs more often in these patients. On the other hand, we have an ever-expanding therapeutic armamentarium to apply in these complex clinical circumstances. Unfortunately, at initial presentation, we can never know exactly what is going to ensue later in these patients' hospital course. Much of the controversy surrounding modern-day management of these patients is not so much about the specific choice of agent or strategy, but rather how to use these agents most effectively in a clinical environment where patients are sent to the catheterization laboratory - often urgently - and then may later require percutaneous or surgical revascularization.

\section{The role of platelets}

Platelets contribute to arterial thrombosis in 5 main ways: adhesion to connective tissue surfaces; activation and granule release; platelet-platelet aggregation; thrombin generation because of a catalytic surface; and localization and stimulus for the activation of inflammatory cells. Complex glycoprotein molecules found on the surface of the platelet membrane act as receptors that mediate attachment to collagen and other platelets through intermediary molecules. An exposed connective tissue surface containing collagen or adherent von Willebrand factor (vWF) or an adherent platelet with exposed GP IIb/ IIIa receptors that bind fibrinogen or $\mathrm{vWF}$ offer a site of attachment for additional platelets. After attachment, the platelet recognizes a stimulus for activation and undergoes a metamorphosis, becoming spiculated in appearance and altering its membrane to act as a catalyst for coagulation enzymes. Activation also triggers the release of storage granules and increased exposure of GP IIb/IIIa, furthering the attachment of additional platelets. Platelet shape change, membrane alteration, granule release, and receptor exposure are all part of the activation process. In addition, the activation process exposes attachment sites for inflammatory cell activators, which is an important step in the initiation of healing but is also partly responsible for the systemic inflammation that accompanies thrombosis. ${ }^{7-9}$

The interaction between platelet receptors and available agents for inhibition is shown in Figure 1.

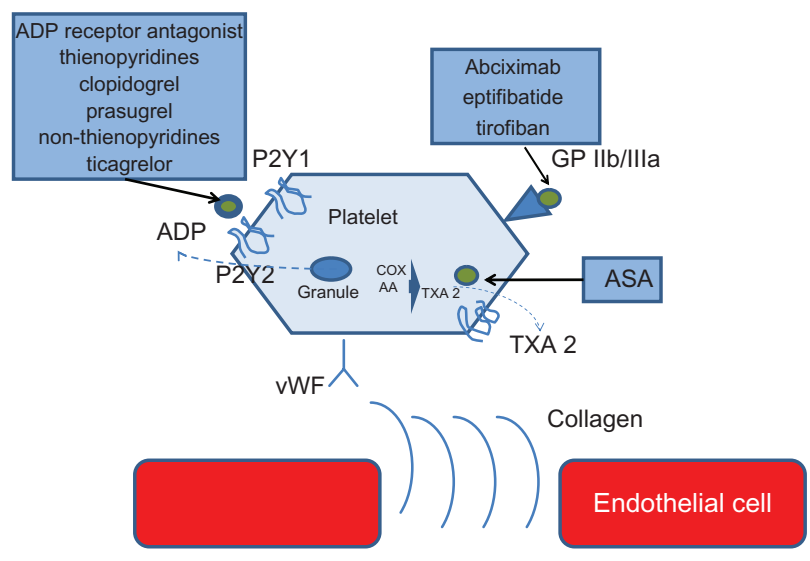

Figure I Schematic of platelets and the sites of action of antiplatelet agents. Abbreviations: $A A$, arachidonic acid; ADP, adenosine diphosphate; $A S A$, aspirin; $C O X$, cyclooxygenase; GP, glycoprotein; TXA2, thromboxane; vWF, von Willebrand factor. 


\section{Acute coronary syndromes, guidelines, and the first thienopyridines}

As discussed above, platelet activation plays a critical role in thrombus formation during plaque rupture leading to ACS. A main element is the activation of the adenosine-diphosphate (ADP) receptor. The ADP receptor binds to the G proteincoupled receptors P2Y12 (Gi/adenylyl cyclase pathway) and P2Y1 (Gq/phospholipase $\mathrm{C} / \mathrm{Ca} 2$ pathway), initiating platelet shape change and activation. More importantly, binding to the P2Y12 receptor amplifies platelet response to other stimuli, such as TXA $_{2}$ and thrombin. ${ }^{10}$

Available agents for inhibiting purinergic platelet activation include the oral thienopyridines ticlopidine and clopidogrel. Both drugs require hepatic metabolism to form an active metabolite that may then irreversibly bind to the P2Y12 receptor. ${ }^{11}$ Surprisingly, mild liver dysfunction does not appreciably affect conversion to the active metabolite. ${ }^{12}$ However, response variability can be affected by absorption, concurrent drug administration, or obesity. ${ }^{13,14}$

Maximal effect on bleeding time is seen after 5 days of ticlopidine administration or after 3 to 5 days of clopidogrel administration and can be hastened by the application of a loading dose. The effects on bleeding time persist for about 1 week after discontinuation of either drug. On the basis of these observations, the 2007 American College of Cardiology/American Heart Assocation (ACC/AHA) guidelines for the care and management of UA/NSTEMI have listed combination antiplatelet therapy with aspirin and clopidogrel (giving the choice of either a 300- or 600-mg loading dose) as a Class Ia recommendation. ${ }^{15}$

In patients who are to be treated medically, clopidogrel should be given at the time that decision is made. In high-risk patients who have indications for early invasive management, either a preprocedural clopidogrel bolus or the institution of GPI is recommended. The combination of all 3 forms of platelet inhibition is labeled a Class IIa recommendation. The duration of therapy is not clearly but rather softly stated as "ideally for one year".

Strong backing of the guidelines is necessary, because clopidogrel is being underused. This is almost certainly the result of bleeding concerns should patients later be referred for coronary artery bypass graft $(\mathrm{CABG})$ surgery. Tricoci and colleagues ${ }^{16}$ studied 61,052 patients with high-risk NSTEACS (defined as the presence of positive cardiac markers, ischemic ST-segment changes, or both) and evaluated temporal trends of clopidogrel use at discharge since the update of the 2002 ACC/AHA guidelines. They found that only 34,319 patients $(56.2 \%)$ received clopidogrel at hospital discharge. Although $96.3 \%$ of patients who underwent PCI received clopidogrel at hospital discharge, only $42.8 \%$ of patients who did not undergo cardiac catheterization and $23.5 \%$ of patients who underwent CABG went home on clopidogrel, despite being admitted to the hospital with high-risk UA/NSTEMI. Apart from PCI, variables favoring receiving clopidogrel at discharge included previous PCI or $\mathrm{CABG}$, stroke, hypercholesterolemia, elevated cardiac markers compatible with a myocardial infarction (MI), and inpatient care by a cardiologist. The authors concluded that while there was in increase in prescribing clopidogrel to NSTE-ACS patients at hospital discharge who had been treated with medical therapy alone or in those who had undergone CABG surgery, most of these NSTE-ACS patients still do not receive clopidogrel at hospital discharge. ${ }^{16}$

The guidelines recommend that dual antiplatelet therapy using aspirin and clopidogrel be administered to the majority of patients with ACS, including those undergoing PCI.

\section{Clopidogrel alternatives}

Because it is often difficult to achieve an adequate pretreatment goal with clopidogrel in clinical practice, more rapid achievement of platelet P2Y12 inhibition may improve patient outcomes. Prasugrel, ticagrelor, and cangrelor are platelet P2Y12 receptor antagonists currently in development that offer faster-acting inhibition of ADP-induced platelet aggregation. These agents act on the same platelet receptor as clopidogrel but are distinguished by their routes of administration, reversibility, and pharmacodynamic properties.

Ticagrelor is the first reversibly binding oral P2Y12 receptor antagonist that blocks ADP-induced platelet aggregation. Unlike thienopyridines, which irreversibly bind to the P2Y12 receptor for the lifetime of the platelet, ticagrelor binds reversibly to the receptor and exhibits rapid onset and offset of effect, which closely follow drug exposure levels. Unlike thienopyridines, ticagrelor does not require metabolic activation. It is quickly absorbed and exhibits a rapid antiplatelet effect, with higher and more consistent levels of inhibition of platelet aggregation (IPA) maintained across the dosing interval than with clopidogrel. Levels of IPA decrease with plasma drug levels after discontinuation. In the phase II Dose confIrmation Study assessing anti-Platelet Effects of AZD6140 vs clopidogRel in non-ST-segment Elevation myocardial infarction-2 (DISPERSE-2) trial of 990 patients with NSTEMI-ACS, ticagrelor treatment with $90 \mathrm{mg}$ and $180 \mathrm{mg}$ twice daily 
showed comparable rates of major and minor bleeding compared with clopidogrel $(75 \mathrm{mg})$, with numerically fewer MIs. Ticagrelor resulted in greater IPA in clopidogrel-naïve patients and produced substantial additional reductions in platelet aggregation activity in patients pretreated with clopidogrel. Ticagrelor treatment was also well tolerated in patients in the DISPERSE-2 trial ${ }^{17}$ and discontinuation rates were comparable to those observed for clopidogrel (Table 1).

An increased risk of mild to moderate dyspnea and mostly asymptomatic ventricular pauses were observed in phase II studies of ticagrelor. The mechanisms for these effects are currently being investigated but appear to be adenosine mediated. The side effects identified during clinical trials are shown in Table 2.

The efficacy and safety of ticagrelor were further evaluated in the phase III PLATO trial, ${ }^{1,18}$ involving more than 18,000 patients with ACS, including both ST-elevation and nonST-elevation ACS. ${ }^{17-19}$ The rhythm abnormalities identified using ticagrelor at the recommended maintenance dose of $90 \mathrm{mg}$ twice a day are shown in (Table 3).

\section{Pharmacodynamics and pharmacokinetics of ticagrelor}

In a double-blind, parallel-group study conducted to assess the pharmacodynamics, pharmacokinetics, and safety of ticagrelor, 200 patients with atherosclerosis were randomly

Table I Clinical end points: number of events

\begin{tabular}{|c|c|c|c|}
\hline End point & $\begin{array}{l}\text { Clopidogrel } \\
75 \text { mg daily } \\
(n=327)\end{array}$ & $\begin{array}{l}\text { Ticagrelor } \\
90 \mathrm{mg} \\
\text { twice daily } \\
(\mathrm{n}=334)\end{array}$ & $\begin{array}{l}P \text { value vs } \\
\text { clopidogrel }\end{array}$ \\
\hline \multicolumn{4}{|c|}{ Through 4 weeks, n (\%) } \\
\hline All-cause death & $2(0.6)$ & $6(1.9)$ & 0.18 \\
\hline CV death & $2(0.6)$ & $6(1.9)$ & 0.18 \\
\hline MI & II (3.5) & $7(2.2)$ & 0.34 \\
\hline Stroke & $\mathrm{I}(0.3)$ & $2(0.6)$ & 0.57 \\
\hline SRI & $2(0.6)$ & $2(0.6)$ & 0.99 \\
\hline RI & $5(1.6)$ & $10(3.2)$ & 0.21 \\
\hline $\mathrm{CV}$ death/MI/stroke & $12(3.8)$ & $14(4.3)$ & $0.7 \mathrm{I}$ \\
\hline \multicolumn{4}{|c|}{ Through I 2 weeks, n (\%) } \\
\hline All-cause death & $4(1.3)$ & $7(2.4)$ & 0.38 \\
\hline CV death & $4(1.3)$ & $6(1.9)$ & 0.54 \\
\hline $\mathrm{MI}$ & $15(5.6)$ & $12(3.8)$ & 0.41 \\
\hline Stroke & $\mathrm{I}(0.3)$ & $2(0.6)$ & 0.57 \\
\hline SRI & $3(1.4)$ & $5(2.3)$ & 0.50 \\
\hline RI & $9(3.0)$ & $13(4.9)$ & 0.29 \\
\hline $\mathrm{CV}$ death/MI/stroke & $17(6.2)$ & $19(6.0)$ & 0.90 \\
\hline
\end{tabular}

Adapted from J Am Coll Cardiol. 2007;50:1844-1851..17

Abbreviations: CV, cardiovascular; MI, myocardial infarction; RI, recurrent ischemia; SRI, severe recurrent ischemia.
Table 2 Crude incidence rates of adverse events

\begin{tabular}{llll}
\hline Event & $\begin{array}{l}\text { Clopidogrel } \\
\mathbf{7 5} \text { mg daily } \\
(\mathbf{n}=\mathbf{3 2 7})\end{array}$ & $\begin{array}{l}\text { Ticagrelor } \\
\mathbf{9 0} \mathbf{~} \mathbf{g} \\
\text { twice daily } \\
\mathbf{( n = 3 3 4 )}\end{array}$ & $\begin{array}{l}\text { P value vs } \\
\text { clopidogrel }\end{array}$ \\
\hline Dyspnea & $2 \mathrm{I}(6.4)$ & $35(10.5)$ & 0.07 \\
Chest pain & $29(8.9)$ & $25(7.5)$ & 0.57 \\
Headache & $28(8.6)$ & $32(9.6)$ & 0.69 \\
Nausea & $1 \mathrm{II}(3.4)$ & $22(6.6)$ & 0.07 \\
Dyspepsia & $9(2.8)$ & $16(4.8)$ & 0.22 \\
Insomnia & $9(2.8)$ & $18(5.4)$ & 0.12 \\
Diarrhea & $1 \mathrm{I}(3.4)$ & $10(3.0)$ & 0.83 \\
Hypotension & $2(0.6)$ & $14(4.2)$ & 0.004 \\
Dizziness & $10(3.1)$ & $14(4.2)$ & 0.53 \\
Syncope & $2(0.6)$ & $4(1.2)$ & 0.69 \\
Rash & $2(0.6)$ & $3(0.9)$ & 1.00 \\
\hline
\end{tabular}

Adapted from J Am Coll Cardiol. 2007;50:1844-1851.17

assigned to receive 50,100 , or $200 \mathrm{mg}$ of ticagrelor twice daily, $400 \mathrm{mg}$ of ticagrelor once daily, or $75 \mathrm{mg}$ of clopidogrel once daily for 28 days. ${ }^{19}$ All groups received aspirin (75-100 mg, once daily). Patients receiving either dosage of ticagrelor had rapidly and nearly completely inhibited ADP-induced platelet aggregation after the initial dose (day 1 ) and at day 28. On day 1, peak final-extent IPA was observed 2 to 4 hours after ticagrelor administration, whereas clopidogrel only minimally inhibited platelet aggregation (mean percentage IPA $<20 \%$ at all time points). Four hours after administration at steady state, the 3 higher doses of ticagrelor produced comparable final-extent IPA, and

Table 3 Arrhythmia events detected on continuous electrocardiography

\begin{tabular}{llll}
\hline & $\begin{array}{l}\text { Clopidogrel } \\
\mathbf{7 5} \mathbf{~ m g} \\
\text { once daily, } \\
\mathbf{n}=\mathbf{2 9 7}, \mathbf{n}(\%)\end{array}$ & $\begin{array}{l}\text { Ticagrelor } \\
\mathbf{9 0} \mathbf{~ m g} \\
\text { twice daily, } \\
\mathbf{n}=\mathbf{3 0 5}, \mathbf{n}(\%)\end{array}$ & P values* \\
\hline $\begin{array}{l}\text { VTs } \\
\text { Patients with sustained } \\
\text { VT }>30 \text { seconds }\end{array}$ & I (0.3) & $0(0.0)$ & 0.49 \\
$\begin{array}{l}\text { Patients with at least } \\
\text { I NSVT }\end{array}$ & $65(22 \%)$ & $67(22 \%)$ & 1.00 \\
$\begin{array}{l}\text { Patients with at least } \\
\text { I triplet } \\
\text { Ventricular pauses }\end{array}$ & $93(31 \%)$ & $89(29 \%)$ & 0.59 \\
$\begin{array}{l}\text { Patients with at least } \\
\text { I pause }>2.5 \text { seconds }\end{array}$ & I3 (4.3\%) & $17(5.5 \%)$ & 0.58 \\
$\begin{array}{l}\text { Patients with }>3 \\
\text { episodes of pauses } \\
>2.5 \text { seconds }\end{array}$ & I (0.3\%) & $6(2.0 \%)$ & 0.12 \\
$\begin{array}{l}\text { Patients with at least } \\
\text { I pause }>5 \text { seconds }\end{array}$ & I (0.3\%) & $5(\mathrm{I} .6 \%)$ & 0.22 \\
\hline
\end{tabular}

Adapted from J Am Coll Cardiol. 2007;50:1844-1851. ${ }^{17}$

Abbreviations: NSVT, nonsustained ventricular tachycardia; VT, ventricular tachycardia. 
ticagrelor was generally well tolerated. All bleeding events, except in 1 patient receiving $400 \mathrm{mg}$ daily, were minor and of mild-to-moderate severity. In this study, ticagrelor doses at 100 and $200 \mathrm{mg}$ twice daily were well tolerated and superior in antiplatelet efficacy to the 50-mg dosage of ticagrelor and to clopidogrel. ${ }^{19}$

The pharmacologic characteristics of clopidogrel, prasugrel, and ticagrelor are shown in (Table 4).

\section{Ticagrelor has greater mean inhibition of platelet aggregation and further suppresses platelet aggregation in clopidogrel- pretreated patients}

A substudy ${ }^{20}$ of the DISPERSE-2 trial compared the antiplatelet effects of ticagrelor and clopidogrel and assessed the effects of ticagrelor in clopidogrel-pretreated patients. Although it has been well documented that clopidogrel combined with aspirin reduces cardiovascular events in patients with ACS, patients with poor inhibition of platelet aggregation with clopidogrel may be less protected. In the substudy, patients were randomly assigned to receive either $90 \mathrm{mg}$ of ticagrelor twice a day, $180 \mathrm{mg}$ of ticagrelor twice a day, or $75 \mathrm{mg}$ of clopidogrel once a day for up to 12 weeks in a double-blind, double-dummy design. One half of the patients also receiving ticagrelor also received a $270-\mathrm{mg}$ loading dose. Patients who received clopidogrel were given a 300-mg loading dose, unless they had already been treated with clopidogrel. ADP-induced platelet aggregation was assessed by optical aggregometry on day 1 and at 4-week intervals. It was found that ticagrelor inhibited platelet aggregation in a dose-dependent fashion and that both doses achieved greater levels of inhibition than did clopidogrel (at 4 weeks, 4 hours after dosing [mean $\pm \mathrm{SD}]$ ): ticagrelor $90 \mathrm{mg}, 79 \%$ [ $\pm 22 \%$ ], ticagrelor $180 \mathrm{mg}, 95 \%$ [ $\pm 8 \%$ ], clopidogrel, 64\% [ $\pm 22 \%]$ ). Ticagrelor also produced further suppression of platelet aggregation in patients previously treated with clopidogrel.
The authors concluded that ticagrelor exhibited greater mean IPA than a standard regimen of clopidogrel in ACS patients and that ticagrelor further suppressed platelet aggregation in clopidogrel-pretreated patients. ${ }^{20}$

\section{Building the evidence: the DISPERSE-2 trial}

The goal of the DISPERSE- 2 trial ${ }^{17}$ was to compare the safety and initial efficacy of ticagrelor with clopidogrel in patients with NSTE-ACS. Evidence had shown that ticagrelor achieves higher mean levels of platelet inhibition than does clopidogrel in patients with stable coronary artery disease. A total of 990 patients with NSTE-ACS, treated with aspirin and standard therapy for ACS, was randomized in a $1: 1: 1$ double-blind fashion to receive either twicedaily ticagrelor (90 mg), once-daily ticagrelor (180 mg), or clopidogrel (300-mg loading dose plus $75 \mathrm{mg}$ once daily) for up to 12 weeks. When analyzed, the primary end point, given by the Kaplan-Meier rate of major or minor bleeding through 4 weeks, was $9.8 \%$ in the ticagrelor 90-mg group, $8.0 \%$ in the ticagrelor $180-\mathrm{mg}$ group, and $8.1 \%$ in the clopidogrel group $(P=0.43$ and $P=0.96$, respectively, vs clopidogrel). Major bleeding rates were $6.9 \%, 7.1 \%$, and $5.1 \%$, respectively $(P=0.91$ and $P=0.35$, respectively, vs clopidogrel). Although not statistically significant, favorable trends were seen in the Kaplan-Meier rates of $\mathrm{MI}$ over the entire study period $(5.6 \%, 3.8 \%$, and $2.5 \%$, respectively; $P=0.41$ and $P=0.06$, respectively, vs clopidogrel). In a post hoc analysis of continuous electrocardiograms, asymptomatic ventricular pauses $(>2.5$ seconds) were more common, especially in the ticagrelor $180-\mathrm{mg}$ group $(4.3 \%, 5.5 \%$, and $9.9 \%$, respectively; $P=0.58$ and $P=0.01$, respectively, vs clopidogrel). In this initial experience, when compared with clopidogrel, there was no difference in major bleeding, an increase in minor bleeding at the higher dose, and encouraging results for the secondary end point of $\mathrm{MI}^{17}$ (Figure 2).

Table 4 Pharmacologic properties of a selection of antiplatelet agents

\begin{tabular}{lllllll}
\hline Drug & Action & $\begin{array}{l}\text { Aggregation } \\
\text { to ADP }\end{array}$ & $\begin{array}{l}\text { Route of } \\
\text { administration }\end{array}$ & Metabolism & $\begin{array}{l}\text { Time to } \\
\text { peak effect }\end{array}$ & $\begin{array}{l}\text { Offset of } \\
\text { action }\end{array}$ \\
\hline $\begin{array}{l}\text { Clopidogrel } \\
300 \mathrm{mg}\end{array}$ & IRR & $\sim 30 \%$ & Oral & $\begin{array}{l}\text { Esterase inactivation and two-step } \\
\text { hepatic CYP-dependent activation }\end{array}$ & $\sim 4$ hours & $\sim 5$ days \\
$\begin{array}{l}\text { Prasugrel } \\
60 \mathrm{mg}\end{array}$ & IRR & $75 \%-80 \%$ & Oral & $\begin{array}{l}\text { Esterase inactivation and one-step } \\
\text { CYP-dependent activation (liver or gut) }\end{array}$ & I-2 hours & $\sim 5$ days \\
Ticagrelor & R & $75 \%-80 \%$ & Oral & $\begin{array}{l}\text { None required } \\
\text { I-2 hours }\end{array}$ & I-2 days ${ }^{32}$ \\
\hline
\end{tabular}

Adapted from. Circulation. 2009; 120:2577-2585 ${ }^{32}$ and Vasc Health Risk Manag. 2010;6:419-429.33

Abbreviations: ADP, adenosine-diphosphate; IRR, irreversible; $R$, reversible. 


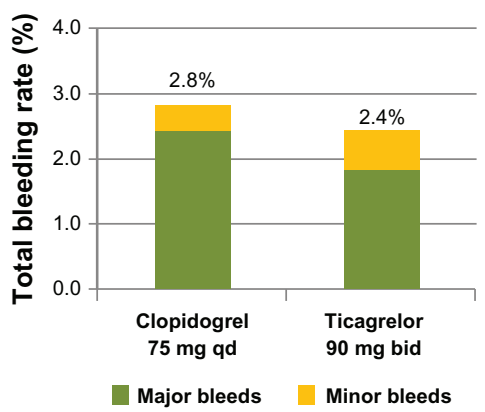

48 hours

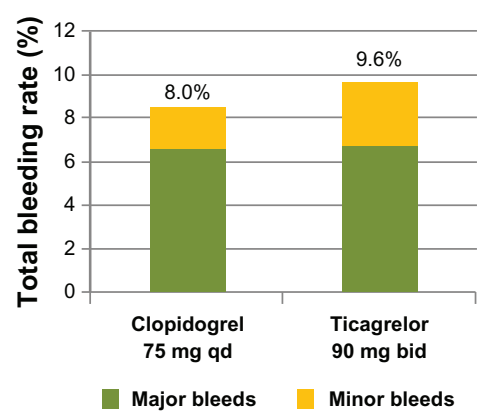

4 weeks

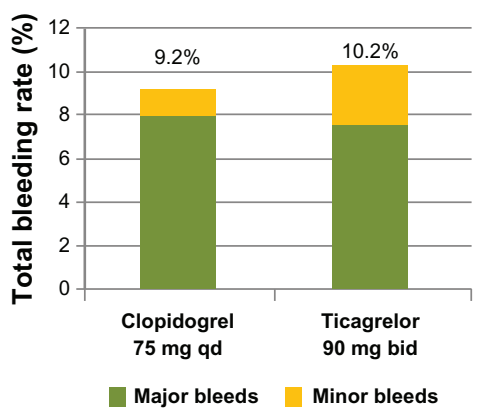

Overall

Figure 2 Rates of major and minor bleeding. Adapted from J Am Coll Cardiol. 2007;50:1844-1851. ${ }^{17}$

Abbreviations: bid, twice daily; qd, once daily.

\section{Ticagrelor in the setting of acute coronary syndromes: the PLATO study}

The PLATO study ${ }^{1}$ is a multicenter, double-blind, randomized trial in patients with ACS comparing 2 treatment strategies: ticagrelor (180-mg loading dose, $90 \mathrm{mg}$ twice daily thereafter) and clopidogrel (300- to 600-mg loading dose, $75 \mathrm{mg}$ daily thereafter). The goal was to evaluate the impact of a more potent platelet inhibitor for the prevention of cardiovascular events. A total of 18,624 patients admitted to the hospital with an ACS, with or without ST-segment elevation, was evaluated. At 12 months, the primary end point - a composite of death from vascular causes, MI, or stroke - had occurred in $9.8 \%$ of patients receiving ticagrelor compared with $11.7 \%$ of those receiving clopidogrel (hazard ratio [HR], 0.84; 95\% confidence interval [CI], 0.77- 0.92; $P<0.001)$. Predefined hierarchical testing of secondary end points showed significant differences in the rates of other composite end points, as well as in MI alone (5.8\% in the ticagrelor group vs $6.9 \%$ in the clopidogrel group; $P=0.005$ ) and death from vascular causes $(4.0 \%$ vs $5.1 \% ; P=0.001)$ but not stroke alone $(1.5 \%$ vs $1.3 \% ; P=0.22)$. The rate of death from any cause was also reduced with ticagrelor $(4.5 \%$ vs $5.9 \% ; P<0.001)$. No significant difference in the rates of major bleeding was found between the ticagrelor and clopidogrel groups (11.6\% and $11.2 \%$, respectively; $P=0.43$ ), but ticagrelor was associated with a higher rate of major bleeding not related to CABG $(4.5 \%$ vs $3.8 \% ; P=0.03)$, including more instances of fatal intracranial bleeding and fewer instances of fatal bleeding of other types.

From the PLATO study, it was concluded that in patients with ACS with or without ST-segment elevation, treatment with ticagrelor as compared with clopidogrel significantly reduced the rate of death from vascular causes, MI, or stroke, without an increase in the rate of overall major bleeding but with an increase in the rate of non-procedure-related bleeding. ${ }^{1}$

\section{Ticagrelor in patients with ACS undergoing planned invasive evaluation}

The PLATO study also evaluated the impact of an invasive strategy and the concomitant administration of ticagrelor versus clopidogrel. At randomization, an invasive strategy was planned for $13,408(72 \%)$ of 18,624 patients. In a double-blind, double-dummy study, patients were randomly assigned in a 1:1 ratio to receive ticagrelor and placebo (180-mg loading dose followed by $90 \mathrm{mg}$ twice a day) or to receive clopidogrel and placebo (300- to 600-mg loading dose or continuation with a maintenance dose followed by $75 \mathrm{mg}$ per day) for 6 to 12 months. All patients were given aspirin. The primary composite endpoint was cardiovascular death, MI, or stroke. The primary composite end point occurred in fewer patients in the ticagrelor group than in the clopidogrel group (569 [event rate at 360 days, 9.0\%] vs $668[10.7 \%]$, hazard ratio $0.84,95 \%$ CI $0.75-0.94$; $P=0.0025)$. There was no difference between the clopidogrel and ticagrelor groups in the rates of total major bleeding (691 [11.6\%] vs 689 [11.5\%], 0.99 [0.89-1.10]; $P=0.8803$ ) or severe bleeding, as defined according to the Global Use of Strategies To Open Occluded Coronary Arteries (GUSTO) trial, (198 [3.2\%] vs 185 [2.9\%], 0.91 [0.74-1.12]; $P=0.3785)$. On the basis of the analysis of the use of a more potent ADP inhibitor in the setting of ACS and following an invasive strategy, ticagrelor appears to be the better option. ${ }^{21}$ 


\section{No genotypic limitations and superior platelet inhibition}

Genetic polymorphisms can affect the platelet response to clopidogrel. Among these, $C Y P 2 C 19$ and $A B C B 1$ genotypes are known to influence the effects of clopidogrel; however, the CYP2C19 genotype does not influence the effects of ticagrelor. ${ }^{22}$ In a substudy of the PLATO trial, ${ }^{23}$ a subgroup of patients underwent genotypic evaluation 10,285 of whom provided samples for genetic analysis. The primary outcome occurred less often with ticagrelor versus clopidogrel, irrespective of CYP2C19 genotype in patients with any loss-of-function allele ( $8.6 \%$ vs $11.2 \%$, HR 0.77 , 95\% CI $0.60-0.99 ; P=0.0380)$ and in those without any loss-of-function allele ( $8.8 \%$ vs $10.0 \%$, HR $0.86,95 \%$ CI $0.74-1.01 ; P=0.0608$ ) (interaction $P=0.46$ ). For the $A B C B 1$ genotype, event rates for the primary outcome were also consistently lower in the ticagrelor group for all genotype groups ( $8.8 \%$ vs $11.9 \%, 95 \%$ CI $0.71,0.55-0.92$ for the high-expression genotype) (interaction $P=0.39$ ). In the clopidogrel group, the event rate at 30 days was higher in patients with loss-of-function CYP2C19 alleles than in those without ( $5.7 \%$ vs $3.8 \% ; P=0.028)$, leading to earlier separation of event rates between treatment groups for the patients with loss-of-function alleles. Patients on clopidogrel who had any gain-of-function CYP2C19 allele had a higher frequency of major bleeding (11.9\%) than did those without any gain-of-function or loss-of-function alleles $(9.5 \% ; P=0.022)$, but interaction between treatment and genotype groups was not significant for any type of major bleeding. Results of this study would suggest that ticagrelor is a more efficacious treatment for ACS than is clopidogrel, irrespective of CYP2C19 and $A B C B 1$ polymorphisms. The implementation of ticagrelor instead of clopidogrel would eliminate the need for the presently FDA-recommended genetic testing for suspected variability in response.

From the PLATO study, there is a platelet inhibition substudy. In this substudy, the inhibitory effects of ticagrelor were compared with clopidogrel during maintenance therapy, using light transmittance aggregometry and ADP as the agonist. It was documented that ticagrelor achieved greater suppression of platelet reactivity than clopidogrel. The mean maximum light transmittance aggregometry responses (ADP, $20 \mu \mathrm{M}$ ) after the maintenance dose were $44 \pm 15 \%$ for clopidogrel and $28 \pm 10 \%$ for ticagrelor $(P<0.001)$. High platelet reactivity was seen more frequently in the clopidogrel group. Proton-pump inhibitor use was associated with higher platelet reactivity with clopidogrel than with ticagrelor. The ticagrelor loading dose also achieved greater inhibition of platelet aggregation than did the clopidogrel loading dose. Therefore, the authors concluded that ticagrelor achieves a greater antiplatelet effect than does clopidogrel in ACS patients, both in the first hours of treatment and during maintenance therapy. ${ }^{24}$

\section{Ticagrelor compared with other potent thienopyridines}

To date, prasugrel and ticagrelor have not been directly compared. Biondi-Zoccai and colleagues ${ }^{25}$ attempted an indirect comparison meta-analysis adjusted by a common control that would enable indirect, adjusted, head-to-head comparisons of 2 treatments originally compared in controlled trials to a common reference treatment. To compare prasugrel and ticagrelor in patients with ACS, 3 randomized trials were used, comprising a total of 32,893 patients: the DISPERSE- ${ }^{17}$ and the PLATO ${ }^{1}$ studies, both comparing ticagrelor and clopidogrel, and the TRITON-TIMI 38 study $^{26}$ comparing prasugrel and clopidogrel.

The overall pooled data for prasugrel and ticagrelor showed that prasugrel and ticagrelor were superior to clopidogrel in reducing the major clinical end points, without any significant difference in stroke or major bleeding, despite more frequent drug discontinuation. An indirect comparison of prasugrel and ticagrelor showed no significant differences in the risk of the main composite end point of death, MI, or stroke or of the individual components. However, risk of definite or probable stent thrombosis was significantly lower with prasugrel (odds ratio [OR] 95\% CI, 0.64 [0.43-0.93]; $P=0.02$, at the expense of a higher risk of any thrombolysis in myocardial infarction [TIMI] major bleeding, OR 95\% CI 1.43 [1.10-1.85]; $P=0.007) .{ }^{25}$

Another indirect comparison of prasugrel (TRITON trial) and ticagrelor (PLATO trial) studied the metabolic side effects and efficacy profile. ${ }^{27}$ For metabolic side effects, ticagrelor increases levels of adenosine, suggesting that the impaired purine catabolism due to increased adenosine levels may cause elevated levels of serum creatinine and uric acid. This phenomenon has not been described with clopidogrel or prasugrel. This study shows that despite the fact that both the creatinine and uric acid levels return to pretreatment values after ticagrelor discontinuation, there is evidence that the alterations in purine metabolism are a real phenomenon, rather than a result of chance. Ticagrelor was clearly superior in efficacy to prasugrel for chronic preventive use because of absolute mortality reduction, realistic second MI prevention, growing over time vascular outcome benefit, 
fewer hemorrhagic fatalities, potentially less CABG-related bleeding events, and lack of cancer risks. ${ }^{27}$

\section{Limitations and side effects}

A detailed evaluation of the study design and the inclusion and exclusion criteria of previous ticagrelor clinical trials reveals several limitations to the general applicability of results. These limitations may limit and subselect the population of patients who may safely receive this medication. Some of the exclusion criteria applied to patients in the ticagrelor studies may bring about concerns about pharmacologic or metabolic interactions, bleeding risk, cardiac rhythm and conduction effects, and overall compliance. Further, there should be careful evaluation and consideration of the side effects identified during the DISPERSE-2 and PLATO trials.

\section{Metabolic interactions}

Possible metabolic interactions that prompt patient exclusion from studies using ticagrelor include concomitant therapy with strong cytochrome P4503A (CYP3A) inhibitors (ketoconazole, itraconazole, clarithromycin, indanivir, grapefruit juice), CYP3A substrates with narrow therapeutic indices (cyclosporine, simvastatin, lovastatin), and strong CYP3A inducers (rifampin, rifampicin, phenyotin, carbamazepine, phenobrabital). During PLATO, some unexplained metabolic findings showed an increased percentage at 12 months in the serum uric acid value from baseline in patients receiving ticagrelor compared with patients receiving clopidogrel ( $15 \pm 52$ vs $7 \pm 31 ; P<0.001)$. There was also a percentage increase in serum creatinine values from baseline values at 12 months $(11 \pm 22$ vs $9 \pm 22 ; P<0.001)$. Currently, the clinical impact of these metabolic changes is unknown, but they warrant careful registry and observation. ${ }^{1}$

\section{Possible enhanced risk of bleeding}

In clinical practice, some patients need chronic anticoagulant therapy; some have known bleeding diathesis or coagulation disorders; and some have a history of intracranial bleeding at any time, of gastrointestinal bleeding within the past 6 months, or of major surgery within the last 30 days. Results of the PLATO trial showed an increase in fatal intracranial bleeding $(0.1 \%$ vs $0.01 \% ; P=0.02)$; however, there were no significant differences compared with clopidogrel in life-threatening or fatal bleeding, by study criteria. There were also no differences in major bleeding or the need for red-cell transfusions. ${ }^{1}$

At this point, there are no recommendations on the concomitant use of ticagrelor, aspirin, and warfarin.
In patients with an ACS and valvular disease (mechanical valve replacement) or atrial fibrillation requiring chronic anticoagulation, the acquired experience with clopidogrel suggests that there is a definite increase in bleeding risk. To decrease that risk, the international normalized ratio should be lowered to between 2.0 and 2.5 and the concomitant administration of the 3 agents (clopidogrel, aspirin, and warfarin) limited to 3 months.

\section{Possible effects on cardiac rhythm and conduction}

Known risks include sick sinus syndrome and second- or third-degree atrioventricular block (unless already treated with a permanent pacemaker). In PLATO, the incidence of ventricular pauses $>3$ seconds identified during Holter monitoring during the first week of therapy was $5.8 \%$ for patients given ticagrelor and $3.6 \%$ for patients given clopidogrel $(P=0.01)$. There was no difference in the number of ventricular pauses at 30 days, the incidence of bradycardia, syncope or heart blocks, or the need for pacemaker insertion. ${ }^{1}$ In the safety and tolerability evaluation of the DISPERSE-2 trial, the post hoc analysis of continuous electrocardiograms showed that mostly asymptomatic ventricular pauses of $>2.5$ seconds were common with ticagrelor at dosages of $180 \mathrm{mg}$ twice daily but not at dosages of $90 \mathrm{mg}$ twice daily when compared with clopidogrel. ${ }^{17}$

\section{Possible noncompliance or poor compliance}

Noncompliance or poor compliance may be due to the need for a twice-a-day administration. Given the increased use of drug-eluting stents and the need to maintain uninterrupted dual antiplatelet therapy in these cases, the discontinuation of ticagrelor in the real world may lead to increased stent thrombosis or atherothrombotic events. The carefully selected patient population and continued surveillance that occurs during clinical trials may provide a false sense of security and increased compliance with therapy.

\section{Dyspnea}

In the PLATO study, there was an absolute $6 \%$ increase in the incidence of dyspnea (HR 1.84, 95\% CI, 1.68-2.02; $P<0.001)$. Although dyspnea led to discontinuation of therapy in less than $1 \%$ of treated patients, its frequency and magnitude did achieve enough significance to be reported. ${ }^{1}$

Apparently, dyspnea while on ticagrelor is not related to abnormalities in pulmonary function tests. In the 
ONSET/OFFSET study, ${ }^{28} 123$ aspirin-treated patients with coronary artery disease who were in stable condition were randomly assigned to receive ticagrelor (180-mg loading dose followed by $90 \mathrm{mg}$ twice daily), clopidogrel (600-mg loading dose followed by $75 \mathrm{mg}$ daily), or placebo. The incidence of dyspnea was $38.6 \%, 9.3 \%$, and $8.3 \%$, respectively $(P<0.001)$. Three patients in the ticagrelor arm had to discontinue the medication because of dyspnea, while none in the clopidogrel or placebo arms did. There were no significant changes in echocardiographic or electrocardiographic findings, serum N-terminal pro-brain natriuretic peptide values, or pulmonary function tests at baseline or 6 weeks after drug administration. Although the mechanism of dyspnea remains unknown, it appears to be related to adenosine-mediated stimulation of pulmonary $\mathrm{C}$ fibers. We do know that ticagrelor inhibits adenosine uptake by erythrocytes. ${ }^{29}$

Given the frequency of dyspnea as a side effect, with reports ranging from $6 \%$ to $38.6 \%$, it may affect longterm compliance if the agent is to be used routinely. For clinicians, it could be problematic during the recovery phase of ACS, because the presence of dyspnea could be confused with an angina equivalent, leading to further testing to exclude ischemia only to ascertain that it is produced by the administration of ticagrelor. As we expand the clinical use of ticagrelor and gain more experience, postmarketing evaluations may shed more light on dyspnea and its clinical impact.

\section{Differences in subgroups and populations}

Another limitation of ticagrelor has been its lack of benefit in certain subgroups of patients in US trials. In the PLATO trial, there was no clear advantage to the use of ticagrelor over clopidogrel in patients with unstable angina. The lack of benefit observed in the US population was a main focus of the FDA's meeting to consider approving ticagrelor. The PLATO trial showed a statistically insignificant trend toward worse outcomes with ticagrelor versus clopidogrel among US patients in the study - who comprised 1800 of the total 18,624 patients. ${ }^{1}$ When considering the composite end point of cardiovascular death, $\mathrm{MI}$, or stroke, rates for the non-US patients were $9.6 \%$ for patients given ticagrelor and $11.8 \%$ for patients given clopidogrel $(H R=0.81)$. In the US population, this benefit was not seen. In fact, the HR actually reversed for the composite end point: $12.6 \%$ for patients given ticagrelor and $10.1 \%$ for patients given clopidogrel $(\mathrm{HR}=1.27)$. Some believe the results could be due to differences in aspirin maintenance doses, which are higher in the United States, because that is the only variable that was correlated with different outcomes between the US and non-US patients. The FDA panelists generally agree that the aspirin factor is probably related to why the US patients did worse with ticagrelor, but they are not certain if that is because of a drug interaction or because the differences in aspirin maintenance dosages are a surrogate for some other unknown difference among patients. Still, the geographic differences in outcomes between different countries are difficult to explain, and those geographic differences in the results from the PLATO trial may have affected the overall results. Although chance may play a role, a prospective evaluation of ticagrelor - once it is approved - will be required to see if the results from PLATO can be duplicated in the postmarketing phase.

\section{What we know about ticagrelor therapy}

Thienopyridines are a class of drugs that function by inhibiting ADP P2Y12 platelet receptors. Currently, clopidogrel, a second-generation thienopyridine, is the main drug of choice, and the combination of aspirin and clopidogrel is administered orally for the treatment of ACS. As an alternative, the third-generation thienopyridine, prasugrel, has been approved for use in Europe and the US since 2009.

All thienopyridines, however, have pharmacologic limitations, and it is these limitations that have led to a search for more effective non-thienopyridine P2Y12 inhibitors. Promising results have been reported with ticagrelor, the first oral, reversible, direct-acting inhibitor of P2Y12 receptors that does not require metabolic activation. Furthermore, ticagrelor has at least 1 active metabolite, which is very similar pharmacokinetically to the parent compound. Therefore, ticagrelor has a more rapid onset and more pronounced platelet inhibition than do other antiplatelet agents. $^{30}$

Ticagrelor selectively and reversibly blocks the P2Y 12 receptor, inhibiting platelet aggregation and preventing amplification of platelet activation. The optimal dosing strategy, as determined by ticagrelor's pharmacokinetic and pharmacodynamic profile, is a loading dose of $180 \mathrm{mg}$ followed by an oral dose of $90 \mathrm{mg}$ twice daily. At these dosages, platelet inhibition is greater with ticagrelor than with clopidogrel (75 mg once daily) in both clopidogrelexperienced and clopidogrel-naïve patients.

Ticagrelor is generally well tolerated; however, minor bleeding, dyspnea, hypotension, nausea, and ventricular pauses have been reported more frequently with ticagrelor 
than with clopidogrel. ${ }^{31}$ Reversible inhibition with ticagrelor may allow for more rapid surgical intervention after discontinuation, suggesting greater flexibility in the treatment of ACS. However, a review of the literature (supported by the actual time to surgery that occurred during PLATO and the platelet inhibition [IPA] reported in the ONSET/OFFSET Study) ${ }^{32}$ suggests that there be at least 3 days between the last dose of ticagrelor and surgery, but that is still shorter than the recommended 5 days for clopidogrel.

\section{Conclusion}

The options for drugs to inhibit the platelet P2Y12 receptor for ADP are rapidly expanding. In addition to ticlopidine and clopidogrel, other well-known compounds of proven antithrombotic efficacy, including prasugrel, which has a higher potency and faster onset of action, have been approved for use in the setting of ACS. The direct and reversible P2Y12 antagonist ticagrelor has shown benefits in clinical trials. Its rapid onset of platelet inhibition and short half-life make it an attractive alternative to thienopyridines, especially when rapid inhibition of platelet aggregation or its quick reversal are required.

We still have more to learn about the safety profile of ticagrelor. The data suggest that more powerful inhibition of the P2Y12 receptor is beneficial. However, it is the clinician's careful consideration when choosing from the available agents that will enable us to tailor the most appropriate antithrombotic therapy for patients. Given the remaining unknowns for chronic ticagrelor therapy and its expanded use in clinical practice, there is a need for careful postmarketing surveillance to better characterize its efficacy and safety profile.

\section{Disclosure}

The authors declare no conflicts of interest.

\section{References}

1. Wallentin L, Becker RC, Budaj A, et al. Ticagrelor versus clopidogrel in patients with acute coronary syndromes. $N$ Engl J Med. 2009; 361:1045-1057.

2. Tricoci P, Peterson ED, Mulgund J, et al. Temporal trends in the use of early cardiac catheterization in patients with non-ST-segment elevation acute coronary syndromes (results from CRUSADE). Am J Cardiol. 2006;98:1172-1176.

3. Ellis SG, Roubin GS, King SB 3rd, et al. Angiographic and clinical predictors of acute closure after native vessel coronary angioplasty. Circulation. 1988;77:372-379.

4. Detre KM, Holmes DR Jr, Holubkov R, et al. Incidence and consequences of periprocedural occlusion. The 1985-1986 National Heart, Lung, and Blood Institute Percutaneous Transluminal Coronary Angioplasty Registry. Circulation. 1990;82:739-750.
5. Zhao XQ, Theroux P, Snapinn SM, Sax FL. Intracoronary thrombus and platelet glycoprotein IIb/IIIa receptor blockade with tirofiban in unstable angina or non-Q-wave myocardial infarction. Angiographic results from the PRISM-PLUS trial (Platelet receptor inhibition for ischemic syndrome management in patients limited by unstable signs and symptoms). PRISMPLUS Investigators. Circulation. 1999;100:1609-1615.

6. Reeder GS, Bryant SC, Suman VJ, Holmes DR Jr. Intracoronary thrombus: still a risk factor for PTCA failure? Cathet Cardiovasc Diagn. 1995;34:191-195.

7. Setzer F, Oberle V, Blass M, et al. Platelet-derived microvesicles induce differential gene expression in monocytic cells: a DNA microarray study. Platelets. 2006;17:571-576.

8. Lindmark E, Tenno T, Siegbahn A. Role of platelet P-selectin and CD40 ligand in the induction of monocytic tissue factor expression. Arterioscler Thromb Vasc Biol. 2000;20:2322-2328.

9. Freedman JE. CD40-CD40L and platelet function: beyond hemostasis. Circ Res. 2003;92:944-946.

10. Storey RF, Sanderson HM, White AE, May JA, Cameron KE, Heptinstall S. The central role of the $\mathrm{P}(2 \mathrm{~T})$ receptor in amplification of human platelet activation, aggregation, secretion and procoagulant activity. Br J Haematol. 2000;110:925-934.

11. Savi P, Herbert JM, Pflieger AM, et al. Importance of hepatic metabolism in the antiaggregating activity of the thienopyridine clopidogrel. Biochem Pharmacol. 1992;44:527-532.

12. Slugg PH, Much DR, Smith WB, Vargas R, Nichola P, Necciari J. Cirrhosis does not affect the pharmacokinetics and pharmacodynamics of clopidogrel. J Clin Pharmacol. 2000;40:396-401.

13. Taubert D, Kastrati A, Harlfinger S, et al. Pharmacokinetics of clopidogrel after administration of a high loading dose. Thromb Haemost. 2004;92:311-316.

14. Feher G, Koltai K, Alkonyi B, et al. Clopidogrel resistance: role of body mass and concomitant medications. Int J Cardiol. 2007;120: 188-192.

15. Anderson JL, Adams CD, Antman EM, et al. ACC/AHA 2007 guidelines for the management of patients with unstable angina/non ST-elevation myocardial infarction: a report of the American College of Cardiology/ American Heart Association Task Force on Practice Guidelines (Writing Committee to Revise the 2002 Guidelines for the Management of Patients With Unstable Angina/Non ST-Elevation Myocardial Infarction): developed in collaboration with the American College of Emergency Physicians, the Society for Cardiovascular Angiography and Interventions, and the Society of Thoracic Surgeons: endorsed by the American Association of Cardiovascular and Pulmonary Rehabilitation and the Society for Academic Emergency Medicine. Circulation. 2007;116:e148-e304.

16. Tricoci P, Roe MT, Mulgund J, et al. Clopidogrel to treat patients with non-ST-segment elevation acute coronary syndromes after hospital discharge. Arch Intern Med. 2006;166:806-811.

17. Cannon CP, Husted S, Harrington RA, et al. Safety, tolerability, and initial efficacy of AZD6140, the first reversible oral adenosine diphosphate receptor antagonist, compared with clopidogrel, in patients with non-ST-segment elevation acute coronary syndrome: primary results of the DISPERSE-2 trial. J Am Coll Cardiol. 2007;50: 1844-1851.

18. James S, Akerblom A, Cannon CP, et al. Comparison of ticagrelor, the first reversible oral $\mathrm{P} 2 \mathrm{Y}(12)$ receptor antagonist, with clopidogrel in patients with acute coronary syndromes: rationale, design, and baseline characteristics of the PLATelet inhibition and patient Outcomes (PLATO) trial. Am Heart J. 2009;157:599-605.

19. Husted S, Emanuelsson H, Heptinstall S, Sandset PM, Wickens M, Peters G. Pharmacodynamics, pharmacokinetics, and safety of the oral reversible P2Y12 antagonist AZD6140 with aspirin in patients with atherosclerosis: a double-blind comparison to clopidogrel with aspirin. Eur Heart J. 2006;27:1038-1047.

20. Storey RF, Husted S, Harrington RA, et al. Inhibition of platelet aggregation by AZD6140, a reversible oral P2Y12 receptor antagonist, compared with clopidogrel in patients with acute coronary syndromes. J Am Coll Cardiol. 2007;50:1852-1856. 
21. Cannon CP, Harrington RA, James S, et al. Comparison of ticagrelor with clopidogrel in patients with a planned invasive strategy for acute coronary syndromes (PLATO): a randomised double-blind study. Lancet. 2010;375:283-293.

22. Tantry US, Bliden KP, Wei C, et al. First analysis of the relation between CYP2C19 genotype and pharmacodynamics in patients treated with ticagrelor versus clopidogrel: the ONSET/OFFSET and RESPOND genotype studies. Circ Cardiovasc Genet. 2010;3:556-566.

23. Wallentin L, James S, Storey RF, et al. Effect of CYP2C19 and ABCB1 single nucleotide polymorphisms on outcomes of treatment with ticagrelor versus clopidogrel for acute coronary syndromes: a genetic substudy of the PLATO trial. Lancet. 2010;376: 1320-1328.

24. Storey RF, Angiolillo DJ, Patil SB, et al. Inhibitory effects of ticagrelor compared with clopidogrel on platelet function in patients with acute coronary syndromes: the PLATO (PLATelet inhibition and patient Outcomes) PLATELET substudy. J Am Coll Cardiol. 2010;56: 1456-1462.

25. Biondi-Zoccai G, Lotrionte M, Agostoni P, et al. Adjusted indirect comparison meta-analysis of prasugrel versus ticagrelor for patients with acute coronary syndromes. Int J Cardiol. 2010. [E-pub ahead of print].

26. Wiviott SD, Braunwald E, McCabe $\mathrm{CH}$, et al. Prasugrel versus clopidogrel in patients with acute coronary syndromes. $N$ Engl J Med. 2007;357:2001-2015.
27. Serebruany VL. The TRITON versus PLATO trials: differences beyond platelet inhibition. Thromb Haemost. 2010;103:259-261.

28. Storey RF, Bliden KP, Patil SB, et al. Incidence of dyspnea and assessment of cardiac and pulmonary function in patients with stable coronary artery disease receiving ticagrelor, clopidogrel, or placebo in the ONSET/OFFSET study. J Am Coll Cardiol. 2010;56:185-193.

29. Björkman JA, Kirk I, van Giessen JJ. AZD6140 inhibits adenosine uptake into erythrocytes and enhances blood flow after local ischemia or intracoronary adenosine infusion. [abstract]. Circulation. 2007; 116:II28.

30. Kowalczyk M, Banach M, Mikhailidis DP, Hannam S, Rysz J. Ticagrelor - a new platelet aggregation inhibitor in patients with acute coronary syndromes. An improvement of other inhibitors? Med Sci Monit. 2009;15:MS24-MS30.

31. Anderson SD, Shah NK, Yim J, Epstein BJ. Efficacy and safety of ticagrelor: a reversible P2Y12 receptor antagonist. Ann Pharmacother. 2010;44:524-537.

32. Gurbel PA, Bliden KP, Butler K, et al. Randomized double-blind assessment of the ONSET and OFFSET of the antiplatelet effects of ticagrelor versus clopidogrel in patients with stable coronary artery disease: the ONSET/OFFSET study. Circulation. 2009;120: 2577-2585.

33. Marczewski MM, Postula M, Kosior D. Novel antiplatelet agents in the prevention of cardiovascular complications - focus on ticagrelor. Vasc Health Risk Manag. 2010;6:419-429.
Core Evidence

\section{Publish your work in this journal}

Core Evidence is an international, peer-reviewed open-access journal evaluating the evidence underlying the potential place in therapy of drugs throughout their development lifecycle from preclinical to postlaunch. The focus of each review is to evaluate the case for a new drug or class in outcome terms in specific indications and patient groups.

\section{Dovepress}

The manuscript management system is completely online and includes a very quick and fair peer-review system, which is all easy to use. Visit http://www.dovepress.com/testimonials.php to read real quotes from published authors. 